\title{
MR. PAASWELL'S APPEAL TO PRODUCING MATHEMATICIANS.
}

BY PROFESSOR C. N. HASKINS.

IT is always a service to the scientific world to set before it a definite statement of some of its important unsolved problems. Such a service Mr. Paaswell has rendered,* in calling attention to certain outstanding mathematical problems of engineering. His thesis is, essentially, that the available mathematical analysis of these problems is, (a) exact, but impracticably complex; or, (b) practicably simple, but inexact; or, (c) nonexistent, save for empirical formulas. He therefore urges producing mathematicians to turn their attention to bettering this state of affairs.

The question naturally arises, "Why does not the engineer himself supply the needed remedy?" Mr. Paaswell suggests several answers, viz.,

(1) The mathematical curricula of the schools of applied science are not sufficiently intensive or extensive.

(2) Modern mathematical treatises and dissertations are so written as to be incomprehensible to those not already familiar with the subject. $\dagger$

(3) "Hardly any treatise has attempted to discuss or analyze the serious problems of the applied science professions."

Of these answers (3) is in effect merely a restatement of the thesis. The suggestion (1) deserves careful consideration. The required mathematical courses of the better schools of engineering represent very nearly the maximum, both in depth and extent, of what can be effectively assimilated and used by the average student in such schools. An increase of significant amount in these required courses would result either in depriving the engineering profession of many useful and successful members, or in lowering the general standard of attainment demanded in those courses. Unquestionably the student engineers of real mathematical aptitude would benefit by the suggested increase. On the other hand a large number of

* Bulletin, vol. 21 (1914), p. 127.

$\dagger$ Mr. Paaswell also contends that "the tone of modern works is not that of disseminating new ideas, but rather that of clothing ideas already familiar to readers in slightly different form." This position seems hardly tenable. Witness, for example, the monographs of the Borel series. 
students who have only moderate mathematical ability, but who nevertheless have compensating qualities which will permit them to develop into useful if not great engineers, would be actually injured by a required course of extent and depth seriously exceeding their powers. Furthermore the mathematically gifted students would not, unless some system of segregation were effected, receive the full benefit of the increased course, since they would be retarded by their less gifted fellows. An increase in the required courses, therefore, appears to be at best an inefficient way of leading to the desired result. Much, however, may be expected of more numerous, broader, and deeper elective courses if a suitable type of student can be encouraged to avail himself of them.

Suggestion (2), however, expresses the real difficulty, and possibly contains implicitly the key to the solution.

The problems mentioned by Mr. Paaswell belong both to engineering and to mathematics. Now engineering and mathematics are two autonomous but friendly professions. The engineer is by virtue of his profession no more a mathematician than is the mathematician an engineer. The engineer's despair of keeping up with the trend of modern mathematical thought has its exact counterpart in the mathematician's despair of keeping up with modern engineering thought and practice. To attack the problems under discussion, however, the despairing engineer needs must add mathematics to his engineering, or the despairing mathematician engineering to his mathematics. Mr. Paaswell suggests the latter alternative, the mathematician may well suggest the former.

The situation described by Mr. Paaswell is, however, not unique in character. In the field of public health there exists an analogous state of affairs, and in that field remedial measures are now being taken which bid fair to lead to a successful result,* and from which we may gather ideas applicable to the present situation.

It has been recognized that, while both physicians and engineers have developed themselves into successful health officers, yet neither the physician nor the engineer is by reason of his own professional training alone wholly competent to attack with success the problems of the control of public health. The demand for officers fitted to cope with these problems has led certain institutions to establish distinct

* Cf. Whipple, G. C., Science, n. s., vol. 40 (1914), p. 581. 
courses to provide both the medical and the engineering training which such officers require. But it is not expected that these courses should be a part of the training of every physician and of every engineer, nor even that every school of medicine or of engineering should establish such courses.

There already exist under university or government control several stations or institutions devoted to research in the problems of engineering. This research is naturally largely experimental, and these stations provide the opportunity of a career for the man who has the aptitude and the desire for this work. If such stations enter upon the field of the mathematical problems of engineering the door will be opened to a career in this line also.

With a definite demand for men competent to attack the mathematical problems of engineering will come the inducement for men to train themselves for the work, and with this inducement, a demand for suitable courses. To meet this demand a few institutions, already strong in both mathematics and engineering, may well organize graduate courses analogous to those which now lead to the degree of Doctor of Public Health.

\section{FUNCTIONS OF LINES.}

Leçons sur les Fonctions des Lignes. Par Vito Volterna. Recueillies et rédigées par Joseph Pérès. Paris, GauthierVillars, 1913. 8vo. vi+230 pp.

THESE lectures were delivered by Volterra at the Sorbonne during the months from January to March, 1912, and were later published as one of the Borel series of monographs on the theory of functions. It would be difficult to determine precisely the historical origin of functions of lines. Special cases of such functions, for example the ordinary definite integral or the integrals of the calculus of variations, have occupied a large share of the attention of mathematicians since the beginnings of the calculus itself. But the conscious formulation of the definition of a function of a line and its derivative, and the study of a general theory, belong to a recent period of investigation in which Volterra has been an earliest pioneer. The development of our knowledge of functions of lines and their applications, since Volterra's 